\title{
Shape Memory Transformation in Mechanically Alloyed Ni-50at\% Ti
}

\author{
S.M. Green, D.M. Grant and J.V. Wood \\ Department of Materials Engineering and Materials Design, University of Nottingham, University Park, \\ Nottingham NG7 2RD, U.K.
}

\begin{abstract}
Ni}$ and $\mathrm{Ti}$ elemental powders have been mechanically alloyed within a horizontal attritor to produce a $\mathrm{Ni}-50 \mathrm{at} \% \mathrm{Ti}$ product that is amorphous upon XRD analysis. Heat treatunent of this product at $500{ }^{\circ} \mathrm{C}$ within an $\mathrm{Ar}$ atmosphere has been shown to promote crystallisation into a $\mathrm{Ni}-\mathrm{Ti}$ intermetallic of $\mathrm{CsCl}$ type parent phase crystallography. Ulpon cooling this parent phase undergoes a solid state thernoelastic shape memory type of phase transformation producing a monoclinic B 19' martensite. This reversible phase transformation has been characterised by differential scaming calorimetry and displays a $M_{s} \leftrightarrow A_{s}$ transfonnation temperature hysteresis of less than $10^{\circ} \mathrm{C}$. This is significantly lower than that associated with commercially produced ingot origin parent phase $\mathrm{Ni}-\mathrm{Ti}$, for which a $30^{\circ} \mathrm{C}$ transformation hysteresis is expected. XRD analysis of the crystallised $\mathrm{Ni}$ - $\mathrm{Ti}$ indicates an increase in the parent phase lattice parameter when compared to $\mathrm{Ni}-\mathrm{Ti}$ synthesised by ingot route. It is proposed that the increased parent lattice parameter effectively reduces the overall lattice strain required for the martensitic phase transformation, enabling the transformation to occur at reduced undercoolings and superheats.
\end{abstract}

\section{INTRODUCTION}

Among the shape memory alloys in current usage, the intermetallic $\mathrm{Ni}-\mathrm{Ti}$ system demonstrates particularly useful material properties. The martensite $\rightarrow$ austenite phase transformation is typically selectable between a temperature range of -50 to $100{ }^{\circ} \mathrm{C}$, dependent upon composition between $\mathrm{Ni} 48-52^{\text {at }} \%$-Ti. Wrought Ni-Ti typically exhibits up to $8 \%$ recoverable plastic strain and possesses a useful combination of material properties, including good ductility, toughness and corrosion resistance [1], which can be enhanced by surface treatment [2]: Ni-Ti demonstrates biocompatibility comparable to $316 \mathrm{~L}$ stainless steel, owing to the presence of an adherent $\mathrm{TiO}_{2}$ surface oxide which prevents $\mathrm{Ni}$ dissolution and release [3]. The material property combination of chemical inertness, high recoverable strain and transformation cyclic stability have been successfully utilised in an ever increasing number of industrial applications, and in particular for biomedical devices from cardiovascular stents to dental archwires and laparoscopic surgical instrumentation. Compositional control is critical to $\mathrm{Ni}$-Ti shape memory transformation behaviour, with \pm 2 at $\% \mathrm{Ni}$ producing up to $200^{\circ} \mathrm{C}$ change in transformation temperature. To achieve the required compositional control, $\mathrm{Ni}-\mathrm{Ti}$ alloys are commercially produced by arc or induction melting with machining to final dimensions following hot working. Arc melting requires multiple remelts to ensure homogeneity, whilst vacuum induction melting has the problem of both crucible and oxygen contamination [4]. Cast Ni-Ti can display segregation and rapid grain growth may occur during high temperature working leading to poor thermal fatigue properties. 
As an alternative, near net shape forming using powder processing routes have been examined by a number of workers [5-7]. These studies have identified problems of large dimensional changes upon sintering, non-uniform stoichiometry, open and closed porosity, loss of the shape memory effect and non-recoverable strain after the first cycle. Porosity in the sintered product is desired for certain applications, such as facial bone replacement, where bone ingrowth into a pore size ranging from 50 to $300 \mu \mathrm{m}$ is required or in low load, large deflection, applications where $50 \%$ strain is possible. However, independent of the desired porosity level, control of the porosity is difficult and is ultimately determined by a combination of the original porosity in the green compact, energy of mixing, the Kirkendall effect and liquid capillary influences. An alternative processing route to near net shape $\mathrm{Ni}$ $\mathrm{Ti}$ is that of mechanical alloying followed by a suitable heat treatment.

Mechanical alloying (MA) is a high energy ball milling technique which has been extensively used to synthesise powders with interdispersed phases (for ductile materials) and to reduce the grain size of brittle materials. MA has also been used with success as a method of atomic scale mixing of elemental powders forming metastable (i.e. amorphous) or stable alloys. This is possible owing to the introduction of a high number of non equilibrium lattice defects during MA which can increase the free energy of the system sufficiently to permit metastable phase formation. $\mathrm{Ni}-\mathrm{Ti}$ is a ready glass former, capable of transformation into a metastable metallic glass under the influence of chemical or thermodynamic driving forces [2][8]. Metallic glasses are characterised by a lack of long range order so slip is difficult and mechanical properties, particularly hardness, are enhanced. However, because of the lack of long range order the crystallographic reversibility is lost and consequently the shape memory effect is destroyed. However, with the introduction of a suitable heat treatment stage, MA offers the advantage of low temperature composition controlled Ni-Ti formation. This study reports some aspects of an on-going project investigating $\mathrm{Ni}-\mathrm{Ti}$ shape memory alloy production from mechanically alloyed elemental $\mathrm{Ni}$ and Ti powders.

\section{EXPERIMENTAL}

Elemental Ni of mean particle size $7 \mu \mathrm{m}(99.9 \mathrm{at} \%)$ and Ti of mean particle $150 \mu \mathrm{m}(99.9$ at\%) were mixed in equiatomic ratio within a horizontal Simolyer laboratory attritor of 2.5 litre capacity. $\mathrm{Cr}$ steel media of mass $1 \mathrm{~kg}$, to provide a charge to media ratio of 10:1, were placed into the attritor chamber which was then vacuumed to better than $1 \mathrm{~Pa}$ and backfilled with dry Ar. The Simolyer attritor design enabled milled powder to be extracted under controlled atmosphere, permitting sampling with progression of milling. The attritor was run continuously for 24 hours at a rotor velocity of $600 \mathrm{rpm}$. A water cooled jacket surrounded the attritor chamber and a thermocouple against the chamber wall provided temperature measurement. Post mechanical alloying, the attrited powder blend was heated to $500^{\circ} \mathrm{C}$ at a rate of $10^{\circ} \mathrm{C} \mathrm{min}-1$ in an $\mathrm{Ar}$ flushed Perkin Elmer 2010 differential scanning calorimeter (DSC). The low temperature phase transformation behaviour of the heat treated powder was also measured in the DSC, cycled from -30 to 130 to $-30{ }^{\circ} \mathrm{C}$ at a rate of $10{ }^{\circ} \mathrm{C} \mathrm{min}{ }^{-1}$ within flowing Ar. Sample sizes for DSC measurement were of the order of $50 \mathrm{mg}$. The DSC provided measurement of the transformation temperatures and enthalpies in additior to the transformation hystereses. $\mathrm{X}$-ray diffraction analysis (XRD) was made upon both the as-attrited powder blend and the crystallised powder within a Siemens Kristalloflex 810 diffractometer using $\mathrm{Cu} \mathrm{K} \alpha$ radiation. To provide a comparison, an ingot synthesised austenitic $\left(A_{f} 13{ }^{\circ} \mathrm{C}\right) \mathrm{Ni}$ $48.9^{\text {at }} \%$ Ti manufactured by the Furukawa Electric Company was also analysed. 


\section{RESULTS \& DISCUSSION}

Scanning electron micrographs of the starting materials are shown in Figure 1. The Ni powder took the form of rough spherical particles and the Ti powder was of irregular morphology but with a smooth surface topography.

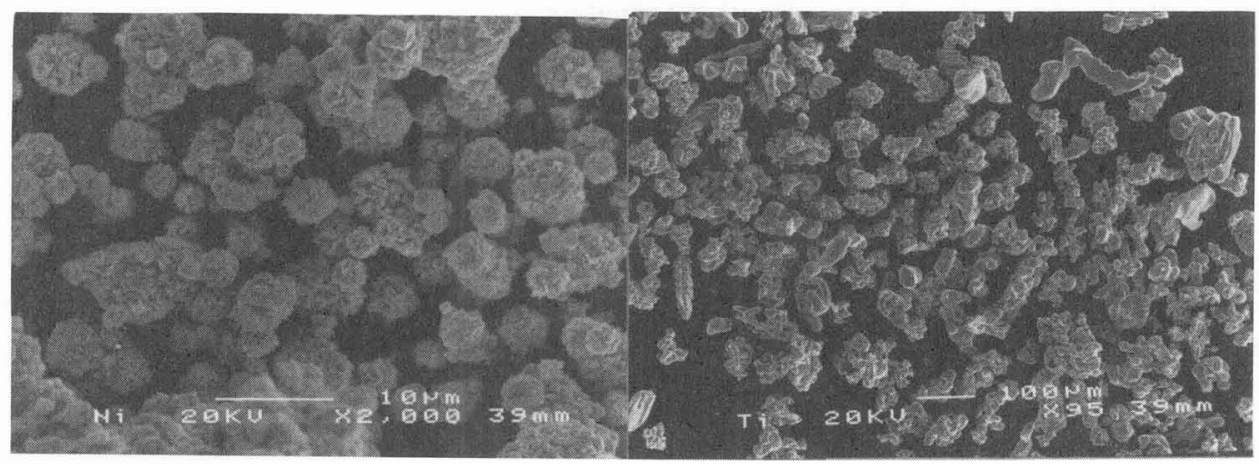

Figure 1 Nickel (left) and Titanium (right) powders prior to attrition

Powder samples extracted periodically during milling indicated that the powder mixture morphology changed as milling progressed. In the early stages of milling, high aspect ratio composite lamellae were produced, of which Figure 2 (left) is typical, illustrating lamellae formed after 5 hours of milling at $600 \mathrm{rpm}$. With increasing milling time, lamellae refinement occurred such that upon completion of milling, the powder blend took the form of varying sized aggregates composed of near spherical particles less than $10 \mu \mathrm{m}$ in diameter. Figure 2 (right) illustrates the morphology of such aggregates upon completion of 24 hours milling at $600 \mathrm{rpm}$.

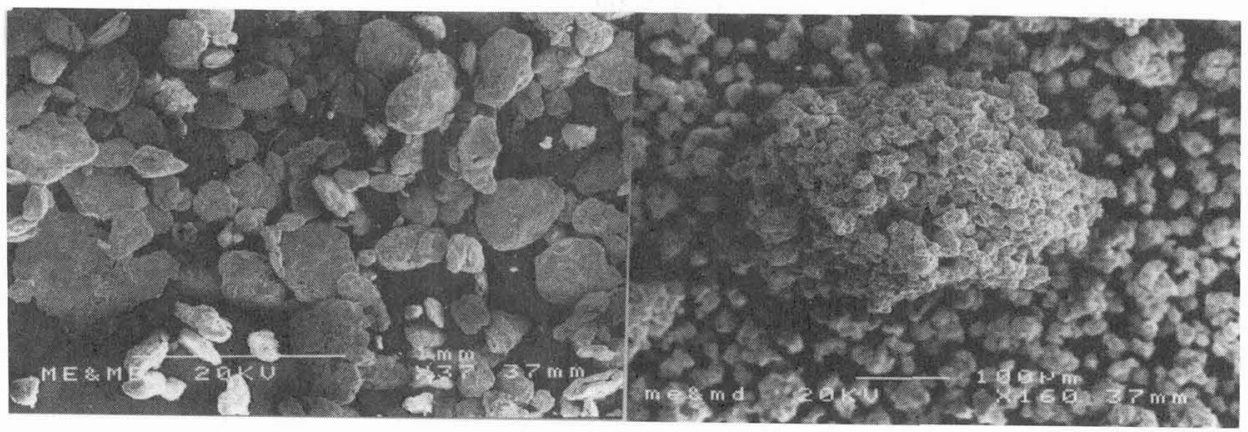

Figure 2 Morphological evolution of attrited $\mathrm{Ni}$ and Ti powders after $5 \mathrm{~h}$ (left) and $24 \mathrm{~h}$ (right)

Lamellae formation during mechanical alloying of ductile materials, such as nickel and titanium, is a well characterised phenomenon. Lamellae are formed by plastic deformation and smearing of the $\mathrm{Ni}$ and $\mathrm{Ti}$ powders in media to media and media to attritor wall impacts in a hammer on anvil type of mechanism that produces progressively finer lamellae [8]. With continued milling, the material within the mill chamber experiences repeated impacts and increased dislocation density such that plastic deformation becomes harder to achieve. Provided that the temperature within the 
chamber remains sufficiently low, recovery will not occur upon repeated impacts and brittle failure becomes prevalent. This change over from ductile to brittle energy transferral within the powder blend can be seen in Figure 2. The lamellae created by plastic deformation (Figure 2 left) are no longer evident upon completion of milling, after 24 hours at $600 \mathrm{rpm}$ (Figure 2 right), replaced instead by agglomerates composed of small particles produced during brittle deformation.

In addition to lamellae evolution and size reduction, XRD analysis highlighted crystallographic changes within the attrited powder mixture. With progression of milling, the phase fraction of elemental $\mathrm{Ni}$ and $\mathrm{Ti}$ decreased, such that after milling for 24 hours at $600 \mathrm{rpm}$, no crystalline phases could be identified, only broad, diffuse maxima characteristic of an amorphous type phase (Figure 3). During milling there is reduction in inter-elemental powder distance with lamellae refinement, combined with local heating caused by mill impacts which accelerates diffusion and alloying. This, coupled with high dislocation densities, promotes metastable amorphous phase formation.



Figure 3 XRD trace of $\mathrm{Ni}$ and $\mathrm{Ti}$ attrited for $24 \mathrm{~h}$ at $600 \mathrm{rpm}$.



Figure 4 High temperature DSC of Ni and Ti attrited for $24 \mathrm{~h}$ at $600 \mathrm{rmm}$.

Phase evolution within the attrited, amorphous powder during heat treatment was followed with DSC. Figure 4 shows the sharp exotherm of enthalpy $-29 \mathrm{Jg}^{-1}$ at a peak 
temperature of $434{ }^{\circ} \mathrm{C}$ measured during the heating of powder attrited for 24 hours at $600 \mathrm{rpm}$. This exotherm, in agreement with Battezzati et al, represents crystallisation of the metastable Ni-Ti phase [9]. This was confrrmed upon XRD re-analysis of the heat treated powder blend, the previously dominant diffuse maxima of the amorphous phase was replaced by sharp peaks characteristic of crystallinity, closely matching the parent phase $(\mathrm{CsCl})$ structure. XRD comparison of the attrited + crystallised Ni-Ti against ingot route parent phase $\mathrm{Ni}-\mathrm{Ti}$ showed a shift to higher d-spacings for the attrited material (Figure 5). Inspection of the XRD peak positions indicated a lattice parameter of 3.017 $\mathrm{nm}$ for the crystallised $\mathrm{Ni}-\mathrm{Ti}$ which compared to $3.009 \mathrm{~nm}$ for the parent phase ingor route $\mathrm{Ni}-48.9^{\text {at }} \% \mathrm{Ti}$ sample.

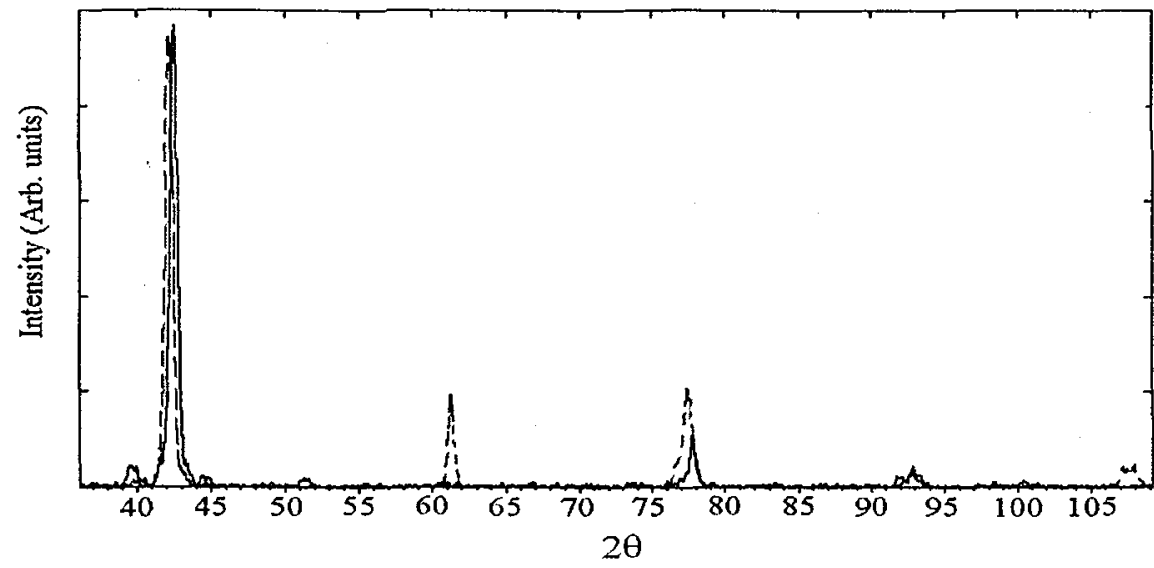

Figure 5 XRD of attrited + crystallised $\mathrm{Ni}$ and $\mathrm{Ti}$ powder blend (broken) and ingot route Ni-Ti (solid)

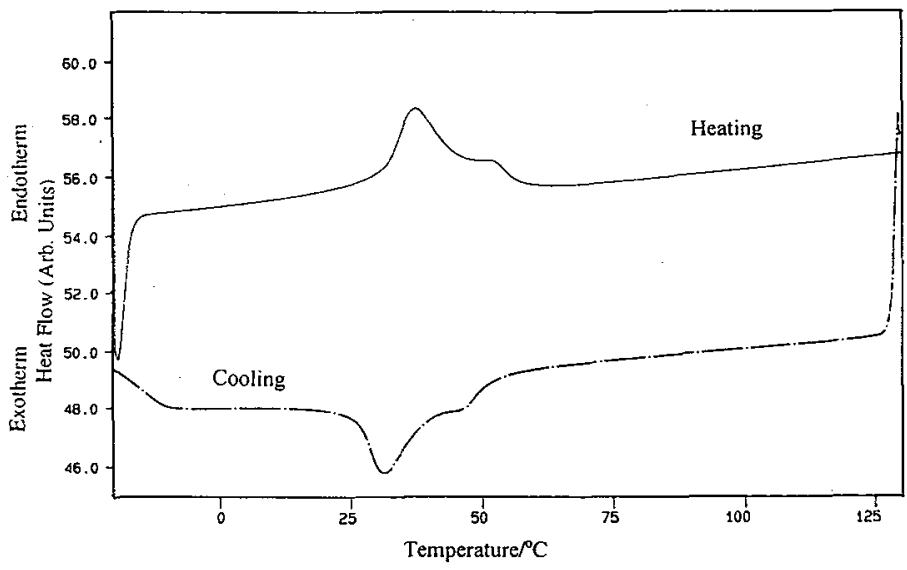

Figure 6 Low temperature DSC of crystallised attrited Ni and Ti powder blend

The parent phase and the occurrence of a reversible thermoelastic phase transformation within the attrited + crystallised $\mathrm{Ni}-\mathrm{Ti}$ was confirmed with low temperature DSC (Figure 6). Comparative DSC measurements were made using ingot route parent phase $\mathrm{Ni}-\mathrm{Ti}$ and Table 1 summarises the characteristic transformation temperatures and enthalpies of the two $\mathrm{Ni}-\mathrm{Ti}$ samples. Although the transformation 
enthalpy of the attrited + crystallised $\mathrm{Ni}-\mathrm{Ti}$ was only $50 \%$ that of ingot route material due to the greater oxide phase fraction from the high surface area powder. However, both the XRD and DSC measurements indicated high homogeneity of the bulk Ni-Ti phase within the powder agglomerates. The attrited + crystallised Ni-Ti demonstrated a very small transformation hysteresis of $6^{\circ} \mathrm{C}$, significantly lower than the $26{ }^{\circ} \mathrm{C}$ hysteresis recorded for the ingot route $\mathrm{Ni}-\mathrm{Ti}$. The transformation hysteresis is a measure of the undercooling and superheating required for the thermoelastic martensitic phase transformation and is influenced by both strain and mismatch between the martensitic low temperature and austenitic parent phase lattices. These results suggest that the slightly larger parent phase lattice of the attrited+crystallised $\mathrm{Ni}-\mathrm{Ti}$, compared to the ingot route $\mathrm{Ni}-\mathrm{Ti}$, has a favourable influence upon the phase transformation, most likely by reducing the lattice strain required for the martensitic phase transformation.

Table 1 DSC determined transformation behaviour of powder attrited + crystallised and ingot route synthesised $\mathrm{Ni}$-Ti.

\begin{tabular}{|l|c|c|}
\hline Ni-Ti Origin & Attrited + crystallised & Ingot route \\
\hline $\mathrm{M}_{s} /{ }^{\circ} \mathrm{C} \pm 0.5^{\circ} \mathrm{C}$ & 43.8 & 10.9 \\
\hline $\mathrm{M}_{\text {peak }} /{ }^{\circ} \mathrm{C} \pm 0.5^{\circ} \mathrm{C}$ & 31.3 & 7.7 \\
\hline Enthalny $\Delta \mathrm{H}(\mathrm{Cooling}) / \mathrm{Jg}^{-1} \pm 0.5 \mathrm{Jg}^{-1}$ & -5.8 & -10.2 \\
\hline $\mathrm{A}_{\mathrm{s}} /{ }^{\circ} \mathrm{C} \pm 0.5^{\circ} \mathrm{C}$ & 30.4 & 27.8 \\
\hline $\mathrm{A}_{\text {peak }} /{ }^{\circ} \mathrm{C} \pm 0.5^{\circ} \mathrm{C}$ & 37.4 & 3.4 \\
\hline Enthalpy $\Delta \mathrm{H}(\mathrm{Heating}) / \mathrm{Jg}^{-1}$ & -5.7 & 11.9 \\
\hline Transformation Hysteresis & 6.1 & 25.7 \\
$\left(\mathrm{M}_{\text {neak }}-\mathrm{A}_{\text {peak }}\right) /{ }^{\circ} \mathrm{C} \pm 0.5^{\circ} \mathrm{C}$ & & \\
\hline
\end{tabular}

\section{CONCLUSIONS}

Equiatomic Ni-Ti intermetallic displaying shape memory behaviour comparable to ingot route synthesised $\mathrm{Ni}-\mathrm{Ti}$ has been produced by a solid state mechanical alloying processing route. After $24 \mathrm{~h}$ attrition at $600 \mathrm{rpm}$, a metastable amorphous Ni-Ti phase was generated which crystallised at $434{ }^{\circ} \mathrm{C}$ with an exotherm of $-29 \mathrm{Jg}^{-1}$. The crystallised $\mathrm{Ni}-\mathrm{Ti}$ demonstrated an $\mathrm{M}_{\text {peak }}$ of $31.3{ }^{\circ} \mathrm{C}$ and an $\mathrm{A}_{\text {peak }}$ of $37.4{ }^{\circ} \mathrm{C}$ and displayed a transformation enthalpy $50 \%$ that of ingot route produced $\mathrm{Ni}-\mathrm{Ti}$. The calculated lattice parameter of the crystallised Ni-Ti was larger than that of ingot route parent $\mathrm{Ni}-\mathrm{Ti}$ and exhibited a very low transformation hysteresis of $6.1{ }^{\circ} \mathrm{C}$ which is believed to be a consequence of reduced transformation lattice strain.

\section{References}

1. Beuhler, W.J., Gilfrich, J.V. and Wiley, R.C. Ocean Eng. 1 (1968) p 105

2. Grant, D.M., Green, S.M., Wood, J.V., Acta Metall. 43 (1995) p. 1045

3. Green, S.M., Grant, D.M., Wood, J.V., Mat. Sci. Eng. A. (1997) In press

4. Funakabo, H. ed. Shape Memory Alloys (Gordon \& Breach Publishers. New York) p.89

5. Igharo, M.. and Wood, J.V. Powder Metallurgy. 28 (1986) p.131

6. Green, S.M., Grant, D.M. and Kelly, N.R. Powder Metallurgy 40 (1997) p. 1

7. Zhang, N., Khosrovabadi, P.N., Lindenhovius, J.H., Kolster, B.H.1992. Mater. Sci. Eng. A150 p. 263

8. Johnson, W.L.1986. Prog. Mat. Sci. 30 p.81

9. Battezzati, L., Cocco, G., Schiffini, L. and Enzo, S. Mat. Sci. \& Eng. A. 97 (1988) pl21 